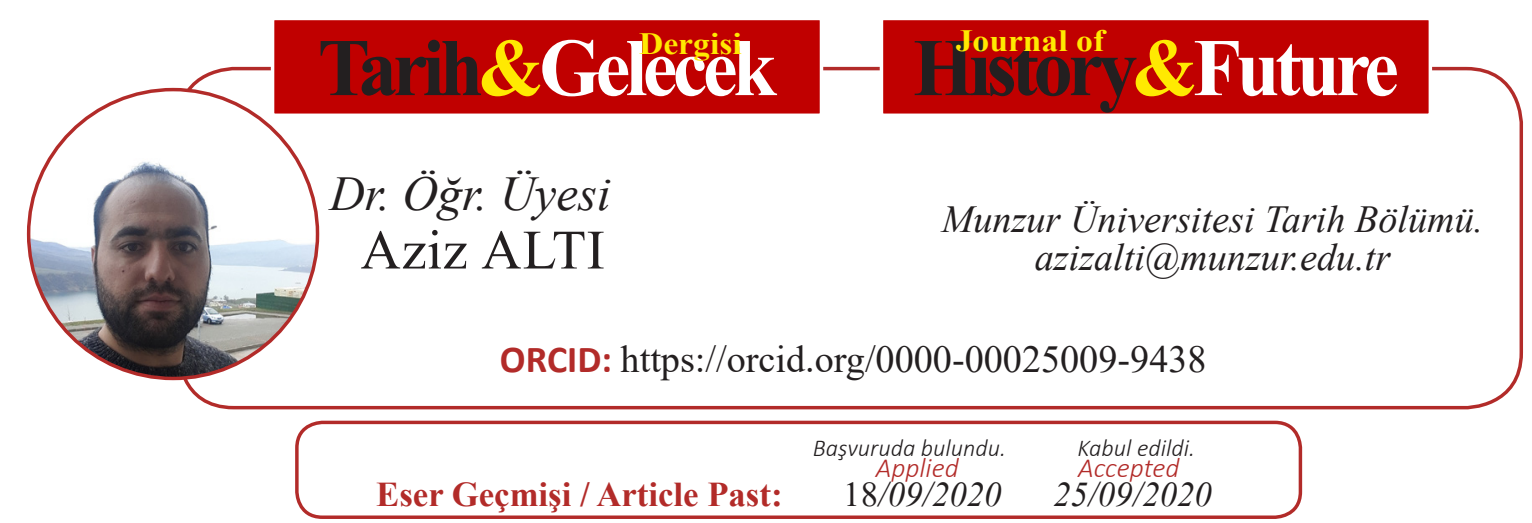

Araştırma Makalesi

DOI: http://dx.doi.org/10.21551/jhf.796892

Research Paper

Orjinal Makale / Orginal Paper

\title{
Yeniçeri Ocağının Yetmiş Birinci Ortası: Seksoncular (Samsoncular)
}

\author{
The Seventy First Troops of the Janissary Guild: Seksoncular \\ (Samsoncular)
}

\section{Öz}

Yeniçeri Ocağının yetmiş birinci ortası olan seksoncular (saksoncular-samsoncular) Fatih Sultan Mehmed tarafından kurulmuştur. Ortanın başında bulunan seksoncubaşı, ocak ağalarındandır. Genel kaideye göre turnacıbaşılar seksoncubaşı olarak atanırken seksoncubaşılar ise zağarcıbaşılığa terfi etmektedirler. Yetmiş birinci ortayı kumanda etmekle vazifeli olan seksoncubașı padişah için av, gösteri ve törenlerde kullanılmak üzere sekson (sakson-samson) cinsi köpek yetiştirmekle görevlidir. Seksoncular 16. yüzyılda bu vazifelerini bostancılara kaptırmış olsa da ortalarında sekson beslemeğe devam etmişlerdir. Seksoncu ortası seksonlara bakmak gibi esas vazifelerinin dışında savaş esnasında kendilerine verilen tüm emirleri ifa etmekle görevliydiler. Barış zamanlarında ise devşirme yapmak üzere vazifelendirilmişlerdir. Seksonların temini gerek ülke içinden gerekse ülke sınırları dışından sağlanmaktaydı. Yetmiş birinci ortadaki ve bostancıların besledikleri seksonların ihtiyaçları devlet tarafından karşılanıyordu. Sekson cinsi köpeklerin kaldıkları mahaller zamanın getirdiği yıpranma ve çeşitli sebeplerden dolayı belirli dönemlerde tamire ihtiyaç duymuştur. Yetmiş birinci orta neferlerinin diğer yeniçeriler gibi aldıkları ulufenin yanı sıra ortalarına ait farklı gelir kalemleri mevcuttu. Seksoncu ortası 1826'da yeniçeri ocağının kapatılmasıyla birlikte lağvedilmiştir. Ele alınan bu çalışmada seksoncu ortasının kuruluşu, ortanın iç işleyişi, işlevleri ile ocaktaki pozisyonu, ortaya sekson temini ve seksonların bakımı gibi konular işlenmiştir.

Anahtar Kelimeler: Yeniçeri Ocağı, Yetmiş Birinci Orta (Seksoncular), Sekson, Av, Tören.

\section{Abstract}

The seventy-first troops (orta) of the Janissaries Guild, the Seksoncular (saksoncular-samsoncular), were founded by Fatih Sultan Mehmed. The seksoncubaş1 at the beginning of the troops is one of the guild chief. According to the general rule, turnacıbaşı are appointed as seksoncubaşı, while seksoncubaş̧ are promoted to zağarcıbaş1. The seksoncubaşı, who is in charge of commanding the seventy-first troops, is responsible for raising a sekson (saksonsamson) breed dog for the sultan to be used in hunting, demonstrations and ceremonies. Although the seksoncular lost their duties to the gardeners in the 16th century, they continued to feed the sekson at the troops. The sekson squad was tasked with performing all the tasks assigned to them during the war, except for their main task, such as taking care of sekson dogs. In times of peace, they were assigned to do recruitment. The seksons were provided both from inside and outside the country. The needs of the seventy-first troops and the seksons fed by the gardeners were met by the state. The areas where the sekson dogs were staying were in need of repair at certain intervals over time and for various reasons. In addition to the salary that the seventy-first troops soldiers received like other janissaries, there were different income items belonging to the troops. In 1826, the sekson troops were abolished with the closure of the janissary corps. In this study, issues such as the establishment of the troops sekson, the inner functioning of the middle, its functions and its position in the janissary guilds, to obtain and the maintenance of the sekson dog are discussed.

Key Words: The Janissary Guild, The Seventy-First Troops (orta), Sekson, Hunting, Ceremony.

ATIF: ALTI Aziz, "Yeniçeri Ocağının Yetmiş Birinci Ortası: Seksoncular (Samsoncular)", Tarih ve Gelecek Dergisi, 6/3 (Eylül 2020), s. (1038-1050) 


\section{Giriş}

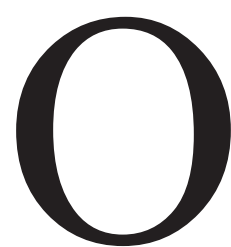

smanlı Devleti'nin daimi ordu ihtiyacını sağlamak adına kuruluş tarihi net olarak bilinmese de I. Murad döneminde kurulduğu genel olarak kabul gören yeniçeri ocağı 1826 yılına kadar varlığını devam ettirmiştir ${ }^{1}$. Ortalardan ${ }^{2}$ meydana gelen yeniçeri ocağ 1 ihtiyaca binaen zaman içerisinde bünyesindeki orta sayılarını arttırmıştır. Kanuni Sultan Süleyman döneminde yeniçeri ocağındaki orta sayısı 165 iken ilerleyen yıllarda bu sayı 196'ya yükselmiş hatta I. Mahmud zamanında 199 olmuştur $^{3}$. Çeşitli alanlarda ihtisaslaşan bu ortalardan birisi de seksoncu(saksoncusamsoncu)lardır. Esasında seksoncularla birlikte farklı cins ve işleve sahip olan köpeklerin bakımını yürütecek farklı ortalarda mevcuttu. Bunlar çeşitli kuş ve sürek avında kullanılan tazılara bakan turnacılar ${ }^{4}$ ile yine avlara katılan zağar cinsi av köpeğine bakan zağarcılardı ${ }^{5}$.

Yeniçeri ortalarında beslenen zağar ve sekson cinsi köpekler zamanla Bostancı Ocağında da beslenmeye başlanmıştır ${ }^{6}$. Sekson cinsi köpekler gerek fiziksel özellikleriyle gerekse kullanıldıkları alanlardaki işlevselliğiyle diğer köpeklerden farklılık arz etmektedir. Esasında av maksatlı kurulan sekson ocağının zamanla gösterilerde veya törenlerde bir güç göstergesi olarak kullanılmasi ${ }^{7}$ ocaktaki seksonlara farklı bir misyon yüklemiştir. Araştırmacılar tarafindan Antik Roma'ya kadar dayandırılan ${ }^{8}$ vahşi hayvan dövüşlerinin zevk ve seyir amacının dışında siyasi maksatlarla yapıldıkları ileri sürülmüştür ${ }^{9}$. Bu doğrultuda özellikle tören ve gösteri gibi umuma açık alanlarda padişaha ait seksonların ayı ve fil gibi iri hayvanların üzerine saldırmaları padişahın karşı tarafa "güç" ve "mücadeleye" yönelik psikolojik mesaj verme amacıyla yapılmış olma ihtimalini ortaya çıkarıyor. Nitekim tazı ve zağar gibi ava yönelik hayvanların mevcudiyetine rağmen iri, güçlü ve saldırgan sekson cinsi köpeklere ocak bünyesinde ayrica yer verilmesi bu kanaati destekler niteliktedir. Bu minvalde ele alınan çalışmada ortanın zuhuru ve gelişimi, işlevleri, seksonların temini ile bakımları gibi konular geniş perspektifte incelenecektir.

1 Kemal Beydilli, "Yeniçeri”, TDVİA, C. 43, İstanbul 2013, 450; Mücteba İlgürel, "Yeniçeriler”, İA, MEB, C. XIII, İstanbul 1986, 385-386.

2 Cemaat ortaları olarak da adlandırılan bu yapı yeniçeri ocağının en eski teşkilatı olup, bugünkü bölük yapılanmasına benzemektedir. Bkz. Mehmet Ali Ünal, Osmanlı Tarih Sözlüğ̈̈ (İstanbul: Paradigma Yayınları 2011), 143.

3 Yeniçeriler ve Bir Yeniçerinin Hatırası, Haz. Kemal Beydilli, (İstanbul: Pınar Yayınları, 2019), 151.

4 Abdülkadir Özcan, “Turnacıbaşı”, TDVIA, C. 41, İstanbul 2012, 428.

5 Abdülkadir Özcan, “Zağarcıbaşı”, TDVİA, C. 44, İstanbul 2013, 75-76; Mustafa Alkan, Ferdi Gökbuğa, "XVI. Yüzyılda Osmanlı Devleti'nde Av Teşkilatı'nın Silistre Sancağındaki Yapılanması”, Gazi Akademik Bakış Dergisi 17, (2015): 26; Ayrıca av o dönemde sıradan bir faaliyet olarak görülmemiş padişahların savaşlarda stratejilerini ve taktiklerini geliştirecek tecrübe organizasyonları olarak algılanmıştır. Bkz. Halil İnalcık, Devlet-i Aliyye II (İstanbul: Türkiye İş Bankası Yayınları, 2014), 9394.

Murat Yıldız, Bahçıvanlıktan Saray Muhafızlı̆̆ına Bostancı Ocă̆ı(İzmir: Yitik Hazine Yayınları, 2012), 224.

Alkan, Gökbuğa, 26.

Gülgûn Üçel Aybet, Avrupa Seyyahların Gözüyle Osmanlı Ordusu (1530-1699) (İstanbul: İletişim Yay1nlar1, 2010), $115-116$.

9 Abdurrahman Uzunaslan, “Antik Roma'da Gladyatör Oyunları”, Süleyman Demir Üniversitesi Fen-Edebiyat Fakültesi Sosyal Bilimler Dergisi 12, (2005): 27. 


\section{Seksoncu Ortasının Kuruluşu Gelişimi ve İlgası}

Sekson (samson) saldırgan iri köpek manasındadır ${ }^{10}$. Uzunçarşılı sekson cinsi köpeği harp köpeği olarak tanımlamaktadır ${ }^{11}$. Bu köpeğin ana vatanının Saksonya ${ }^{12}$, cinsinin ise mastiff olduğu ifade edilmektedir ${ }^{13}$. Evliya Çelebi, bu köpek türünü aslana, Cezayir canavarına benzetmekte ve Kastamonu'nun “cılâv katırı” büyüklüğünde olduğunu vurgulamaktadır. Ona göre sekson köpekleri iki adamı sürükleyecek kadar güçlüydü ${ }^{14}$.

Seksoncu ortanın kuruluşu Fatih Sultan Mehmed'in saltanat yıllarına denk gelmektedir. Eflak'tan Fatih Sultan Mehmed'e üç, dört tane tazı ile birlikte birkaç sekson gönderilmesinin ardından padişah; "onları beslemeye başka bir oda olsa" buyurduğunda seksoncu ortası kurulmuştur. Padişahın emrine binaen o zamanın en yaşı ı ihtiyar yayabaşısı 25 akçe yevmiye ile seksoncubaşı olarak tayin edilmiştir. Seksoncubaşının ardından ortaya bir de seksoncu kethüdası atanmıştır. Seksonlar içinse ekmek ${ }^{15}$ istihkakı verilmiştir. Seksoncu ortasının yanında seksonların kalacağı mekânların yanı sıra Tophane üzerinde bir de yayla tahsis edilmiştir ${ }^{16}$. Evliya Çelebi yeniçeri ocağında bulunan seksonların Samsonhane mesirgahı olarak adlandırılan mesirede yaylaya çıkartıldığından bahseder ${ }^{17}$. Padişahın avlarına katılmaları kanunlaşan seksoncuların av esnasında uzun etekli gömlek giymeleri ve ellerinde ucu gümüşlü değnek taşımaları kural haline getirilmiştir ${ }^{18}$. Yetmiş birinci ortanın nişanının şekli konusunda kırmızı renkte olduğu ve üzerinde sekson resminin yer aldığı belirtilmiştir ${ }^{19}$. Seksoncu ortasının mevcuduna bakıldığında bu orta 1623 senesinde 350 kişiyken 1664 yılında 531 kişiydi ${ }^{20}$. Seksoncuların sayısı 18. yüzyılın ikinci yarısında 200 kişi civarındaydı ${ }^{21}$.

10 Abdurrahman Vefik Sayın, Tekâlif Kavaidi (Ankara: T.C. Maliye Bakanlığı Yayınları, 1999), 205.

11 İ.H. Uzunçarş1lı, Osmanlı Devleti'nin Saray Teşkilatı, (Ankara: TTK, 1988), 468-469.

12 Yildiz, 224.

13 M. Mert Sunar, “Osmanlı Devleti'nde Arslanhane”, Toplumsal Tarih, (2018): 39.

14 Evliya Çelebi b. Derviş Mehemmed Zillî, Evliya Çelebi Seyahatnamesi 1. Kitap, Haz. Robert Dankof, vd. (İstanbul: YKY, 2006), 218, 279.

15 Seksonlara verilen bu ekmek muhtemelen Ayasofya yakınlarındaki sekban firınında pişiriliyordu. Bu fırın "fodla fırını” namıyla Fatih Sultan Mehmed zamanında av köpeklerini beslemek amacıyla yapılmıştı. Fodla kepekli undan yapılan bir pide çeşidi idi. Bkz. Üçel, 76.

16 Kavanin-i Yeniçeriyan, Tayfun Toroser (Haz.), (İstanbul: Türkiye İş Bankası Yayınları, 2011), 143.

17 Evliya Çelebi b. Derviş Mehemmed Zillî, Evliya Çelebi Seyahatnamesi 1. Kitap, 218.

18 Kavanin-i Yeniçeriyan, 143.

19 İBBAK K0456 numaralı yazma eser, s. 69.

20 İ.H. Uzunçarşıl1, Osmanlı Devleti Teşkilâtından Kapukulu Ocakları I, (Ankara: TTK, 1988), 203.

21 Abdülkadir Özcan, “Saksoncubaşı”, TDVİA, C. Ek-2, İstanbul 2016, 456. 


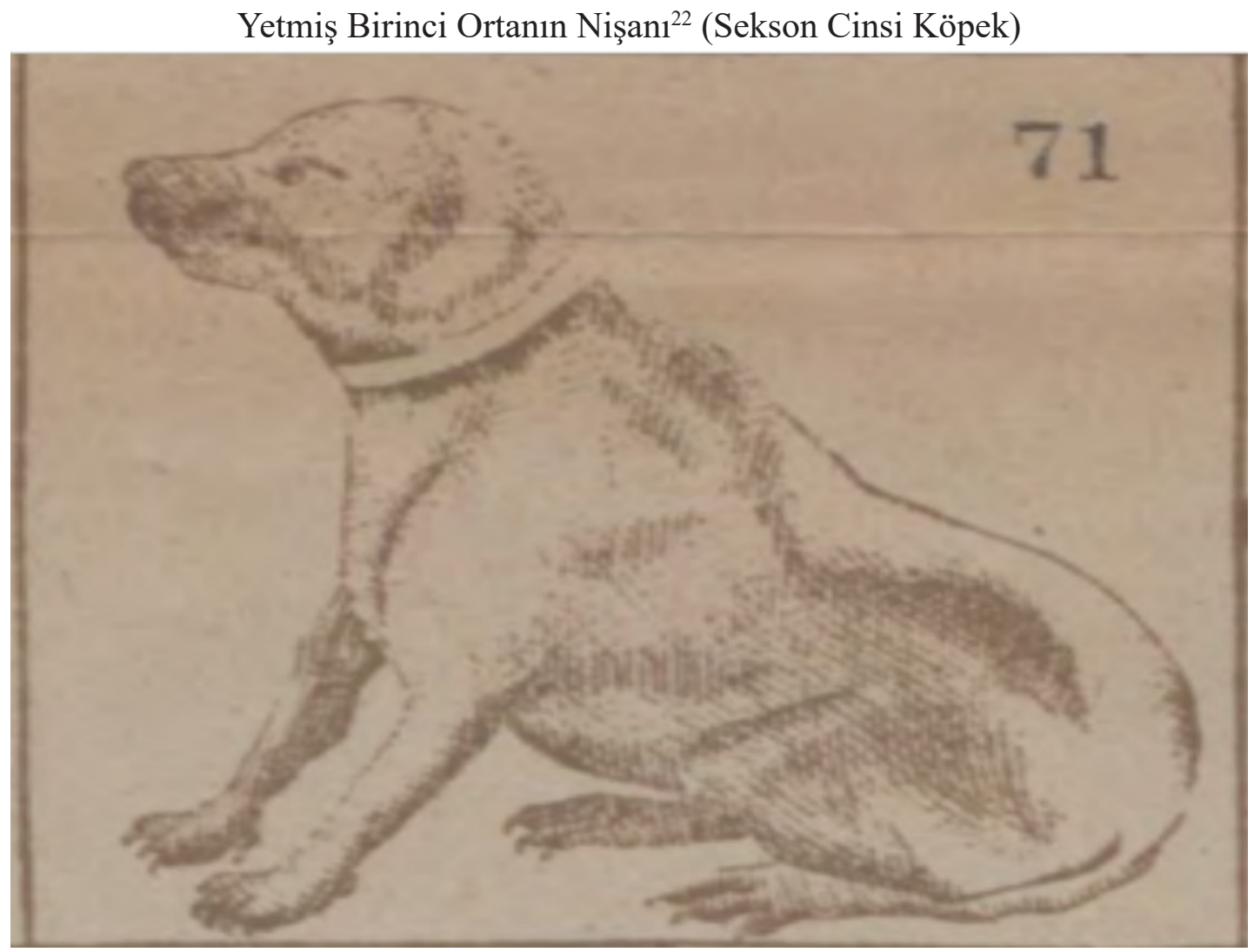

Seksoncubaşı Yeniçeri ocağının büyük zabitlerindendir²3. İçlerinde seksoncubaşının da yer aldığı bu büyük zabitlere "Ocak Ağaları" ya da "Katar Ağaları" adı verilmekteydi²4. Terfi ettiklerinde yüksek ihtimalle zağarcıbaşı olurlardı ${ }^{25}$. Bu doğrultuda 1597 yılında seksoncubaşı olan Muharrem Ağa, zağarcıbaşılığa atanmıştır ${ }^{26}$. Yine zağarcıbaşının görevden alınmasının akabinde silsile gereği seksoncubaşı olan İsmail Ağa, zağarcıbaşılığına terfi etmiştir ${ }^{27}$. Seksoncubaşılık makamına ise genelde turnacıbaşı atanmaktaydı 15 Kasım 1798 tarihinde Turnacıbaşı Hasan A ğa'ya seksoncubaşılık tevcih edilmiştir ${ }^{28}$. 16. yüzyılın ikinci yarısında seksoncubaşılara eğer taşrada tımar tevcih edilirse kendilerine zeamet verilirdi ${ }^{29}$. Yine seksoncubaşılara taşrada idarecilik verildiğinde genelde sancakbeyliğine tevcih edilirlerken bazı zamanlar seksoncubaşılar

Graf Marsilli, Osmanlı Imparatorluğunun Zuhur Ve Terakkisinden Inhitatı Zamanına Kadar Askerî Vaziyeti, M. Kaymakam Nazmi (Çev.), (Ankara: Büyük Erkanıharbiye Matbaası, 1934), Şekil 16.

23 M. Z. Pakalın, Osmanlı Tarih Deyimleri ve Terimleri Sözlüğ̈̈ 3 (İstanbul: MEB, 1983), 112.

24 Yeniçeriler ve Bir Yeniçerinin Hatırası, 151.

25 Hezarfen Hüseyin Efendi, Telhisü'l-Beyan Fi Kavanin-i Al-i Osman, Sevim İlgürel (Haz.). Ankara: TTK, 1998 ), 148.

26 Topçular Katibi 'Abdülkâdir (Kadrî) Efendi, Topçular Katibi 'Abdülkâdir (Kadrî) Efendi Tarihi I, Ziya Yılmazer (Haz.), (Ankara: TTK, 2003), 203.

27 İstanbul'un Uzun Dört Y1lı (1785-1789) Taylesanizâde Hâfız Abdullah Efendi Tarihi, Feridun M. Emecen (Haz.), (İstanbul: Tatav Yayınları, 2013), 107.

28 COA HAT. 1436/59032. Bu vesikaya göre Zağarcıbaşı Kul Kethüdalığına, Seksoncubaşı Zağarcıbaşılığa, Turnacıbaşı Seksoncubaşılığa, Muhzır Ağa Turnacıbaşılığa, Kethüdayeri ise Muhzır Ağa'lığa atanmıştır. Benzer örnek 1814 yılına ait teşrifat defterinde de yer almaktadır. Bkz. COA D.TŞF.d. 26099/2.

29 Uzunçarş1l, Osmanlı Devleti Teşkilâtından Kapukulu Ocakları I, 203. 
beylerbeyi olarak da atanmışlardır ${ }^{30}$. Seksoncubaşılar aynı zamanda yeniçeri ağasının meclisinde aza sıfatıyla yer alıyordu ${ }^{31}$. Seksoncubaşı, solak, turnacı ve hasekiler gibi rikab-1 hümayunun ${ }^{32}$ önemli aktörlerindendi ${ }^{33}$. Seksoncuların padişaha bu denli yakın oluşları elbette onları daha önemli kılıyordu. Seksoncubaşının kıyafetine bakıldığında sorgucuna balıkçıl koyar, samur ve vaşak kaplı kadife üst giyerlerdi. Atının zinciri gümüşten olan seksoncubaşının topuz ve üzengisi de gümüştendi ${ }^{34}$. Seksoncubaşılar terfi ettiği gibi görevi ihmal ve kanuna aykırı davrandıklarında görevlerinden azlediliyorlardı. Nitekim 1818 senesinde seksoncubaşı olan Mustafa Ağa kendi halinde olmadığ 1 ve kanunsuz işlere bulaştığ 1 için görevinden azledilip Mağosa kalesine sürgün edilmişsirir ${ }^{35}$.

16. yüzyılın sonlarında seksoncu ortasına günlük kırk altı, sekiz nefer seksoncu bölükbaşısına sekizer, seksoncu kethüdasına ise dört çift fodula veriliyordu. Seksoncu odasına tahsis edilen koyun eti haricinde seksoncubaşı'ya ayrıca bir koyun veriliyordu. Ulûfe dağıtımı sırasında ocağın önemli komutanlarına akide şekeri verilmekteydi. Bu doğrultuda seksoncubaşı'ya da 20 dirhem şeker verilirdi ${ }^{36}$. Seksoncu ortasının bazı ihtiyaçları reayanın çeşitli alanlarda mükellef tutulmalarıyla giderilmeye çalışılmıştır. Seksoncu ortasında akşamları yanan kandil için gerekli olan yağ ihtiyacının bir kısmı İstanbul'da yaşayan Nikofolli tarafından karşılanıyordu. Nikofolli yerine getirdiği bu yükümlülüğü karşıllğ̆nda cizye ${ }^{37}$ vergisinden muaf tutulmuştu ${ }^{38}$. Yine Perakin adlı zımmi de her y1l yetmiş birinci ortaya 80 vukiyye $^{39}$ zeytin yağ vererek avarız-1 divaniye ve tekâlif-i örfiye'den muaf oluyordu ${ }^{40}$. Ocağın bir başka geliri ise kendi neferlerinden kalan muhallefatdır. Yetmiş birinci ortanın neferlerinden olan kişiler İstanbul'da ya da başka yerde vefat eder ve geride mallarını bırakacak varisçisi yoksa bu kişilere ait olan mallar devlet hazinesine değil de yetmiş birinci ortanın ihtiyaçları için buraya aktarılmaktadır ${ }^{41}$. Ocak kendine ait mülkü yoluyla da gelir elde ediyordu. Bilindiği üzere yetmiş birinci ortanın Beyoğlu'ndaki yazlıkları civarında koruhaneleri bulunmaktaydı. Ancak burası Tophane kışlasına ilave edilmesinden dolayı sene de 60 kuruş miri'den seksoncular ortasına verilmekteydi ${ }^{42}$. Bu da ortaya ayrı bir kaynak teşkil ediyordu.

30 Abdülkadir Özcan, "Saksoncubaşı", 456.

31 Ahmed Cevad Paşa, Tarih-i Askerî-i Osmanî, Kitab-ı Evvel: Yeniçeriler: Yeniçerilerin İhdasından Ilgasına Değin Ahval-i Tarihlerini Bahisdir, (İstanbul: Kırk Anbar Matbaası, 1299), 22.

32 "Padişahın huzur" manasına gelmektedir. Bkz. Abdülkadir Özcan, "Rikab”, TDVİA, C. 35, İstanbul $2008,110$.

33 Topçular Katibi ‘Abdülkâdir (Kadrî) Efendi, 728.

34 Hezarfen Hüseyin Efendi, 148; Eyyubî Efendi Kanûnnâmesi, Haz. Abdülkadir Özcan, (İstanbul: Eren Yayınc1lık, 1994$), 44$.

35 C.AS. 403/16640.

36 Abdülkadir Özcan, "Saksoncubaşı", 456.

37 Baş vergisi olarak da adlandırılan bu vergi Osmanlı Devleti'nin 14-75 yaş arasındaki (vergi verme yükümlülüğüne sahip) gayrimüslim erkek tebaasından senede bir kereye mahsus olmak üzere aldığ 1 şeri bir vergidir. Bkz. Kazım Kartal, “1840-1850 Tarihlerini Kapsayan Balıkesir Ve Bigadiç Kazaları Cizye Defterlerinin Tanıtımı Ve Tahlili”, Birey ve Toplum Sosyal Bilimler Dergisi 10, (2020): 29.

38 “... İstanbul'da vaki dergah-l ali yeniçeri ortalarından yetmiş bir seksoncular cemaatinin ortalarında yanan kanadil içun kendu malımdan senede bir defa seksan vuklyye revgan-ı zeyt virmek şartıyla üzerime edası lazım gelan cizye-i şeriyemi eda eyledikden sonra ... Bende Nikofilli”. COA AE.SOSM.III 17/1112.

39 Ukiyye ya da kıyye ismiyle de anılmaktadır. Bunlar okka adlı ağırlık ölçüsünün diğer ismi olup 400 dirhemdir. 1 dirhemin 3,2075 grama denk geldiği bilindiğinden 400 dirhem yaklaşık olarak 1.283 grama denk gelmektedir. Bkz. Ünal, $198,404$.

40 COA İE. AS. 57/5147; COA A.DVNS.MHM.d. 131/1209.

41 TS.MA.e. 690/33.

42 COA C.AS. 466/19465. 
Seksoncu ocağının kaldığı kışlalar zamanın getirdiği yıpranmalar ve doğal afetler neticesinde tahribata uğruyordu. Buna benzer olaylar karşısında yapılar tamire ya da yeniden inşaya ihtiyaç duyuyordu. III. Selim döneminde ise seksoncuların kaldığı kışlanın yeniden inşası gündeme gelmişti ${ }^{43}$. 1801 yılında İstanbul'da meydana gelen depremde diğer yapılar gibi seksonhane de zarar görmüştür ${ }^{44}$. İlerleyen senelerde meydana gelen yangın ve tahribatla seksonların kalacakları yerler harap olmuştur. Durum o kadar vahim hale gelmiştir ki seksonlar Dolmabahçe civarından döndüklerinde kalacak yerleri yoktur. Mevcut durumu arz eden ortanın ihtiyarı biran evvel buraya gereken tamirin yapılmasını istemiştir. Talebin olumlu karşılanması neticesinde seksonhaneye keşif gerçekleşmiş ve seksonhanenin tamire muhtaç olduğu anlaşılmıştır. Keşfi Hassa Mimarbaşı Hafız Mehmed Emin yapmıştır. Keşif neticesinde inşa masrafı olarak 6878 buçuk kuruş maliyet çıkmıştır ${ }^{45}$. 1826'ya kadar faaliyetlerine devam eden seksoncu ortası Yeniçeri ocağının kapatılmasıyla ortadan kalkmıştır ${ }^{46}$.

\section{Seksoncu Ortasının Vazifeleri}

Sekson cinsi köpeklerin bakım ve idaresiyle ilgilenen askere seksoncu, seksoncuların başındaki kişiye ise seksoncubaşı denilmektedir ${ }^{47}$. Yetmiş birinci ortanın bakımını yürüttükleri seksonlar bilhassa ayı avında kullanılmaktayd1 ${ }^{48}$. Birinci vazifeleri padişahın sürek avına katılmak olan seksoncular aynı zamanda bayramlarda ve önemli günlerde gerçekleşen biniş-i hümayun ${ }^{49} l a r d a ~ d a ~ k u l l a n ı l ı y o r d u^{50}$. Bu doğrultuda seksonların temel vazifelerinin şikar-1 hümayun olarak adlandırılan padişah avlarında ve biniş-i hümayun olarak adlandırılan padişah gezilerinde kullanıldıkları anlaşılmaktadır ${ }^{51}$. Yetmiş birinci ortanın seksoncuları ocak talimlerinde özelikle padişahın katıldığı talimlerde gösterilerde bulunurdu. Yeniçeri atışlarını seyretmek amacıyla Kanuni Sultan Süleyman döneminde talimhanede padişaha ait bir yer yapılmıştır. Padişah senede bir kez buraya gelerek atış talimlerinde bulunurdu. Padişahın bu gelişlerinde hazır bulunan seksoncular seksonları ayıların üzerine saldırtırlardı ${ }^{52}$. Topçular Katibi Abdülkadir, padişahın geçişi esnasında gümüş ve altın zincirlerle bağlanmış olan seksonların seksoncular tarafindan hazır halde bekletildiklerini aktarmıştır ${ }^{53}$. Yine aynı kaynağın belirttiği üzere 1613 yılında Uzunköprü'de yapılan sürgün avında ceylan, tavşan, tilki, kurt, ayı ve daha birçok hayvan avlanılmış ve bazıları zağar ve seksonlara parçalatılmıştır ${ }^{54}$. Ancak vesikaların bizlere aktardığ 1 bilgi doğrultusunda seksoncu ortasında yalnızca seksonların olmadığı anlaşılmaktadır. Nitekim vesikalarda seksoncu

44 TS.MA.e. $670 / 35$.

45 COA C.AS. 130/5795.

46 Abdülkadir Özcan, "Saksoncubaşı", 456.

47 Sayın, 205.

48 Graf Marsilli, Osmanlı Imparatorluğunun Zuhur Ve Terakkisinden İnhitatı Zamanına Kadar Askerî Vaziyeti, M. Kaymakam Nazmi (Çev.), (Ankara: Büyük Erkanıharbiye Matbaası, 1934), 79; Abdülkadir Özcan, “Saksoncubaşı”, 456.

49 Buna "biniş-i saltanat" adı da verilmekteydi. Bunlar padişahın genelde küçük ve tören şeklinde düzenlenen gösterişli gezilerine verilen isimdir. Bkz. Abdülkadir Özcan, "Biniş”, TDVİA, C. 6, İstanbul 1992, 184.

50 “Ayad-ı saidede biniş-i hümayun vukuunda lüzumu vecihle kullanılmak içun Seksonhane ocağında güzide seksonlar...” COA HAT. 39/1952; COA HAT 1140/45357.

51 COA A.DVNS.MHM.d. 81/563; COA HAT. 39/1952.

52 Uzunçarşıl1, Osmanlı Devleti Teşkilâtından Kapukulu Ocakları I, 332.

53 Topçular Katibi ‘Abdülkâdir (Kadrî) Efendi, 136.

54 Topçular Katibi ‘Abdülkâdir (Kadrî) Efendi, 614. 
ortasında devlete ait ayıların varlığ 1 da görülmektedir ${ }^{55}$. Özellikle gösterilerde ve törenlerde seksonlar bu ayıların üzerine bırakılırd ${ }^{56}$. 1740-41 yılında yapılan gösterilerde iki sekson köpeği bir ayının üzerine saldırtılmış ancak iki sekson bir ayıya baş edememiştir. Fakat üçüncü seksonun da salınması neticesinde köpekler ayıyı alt etmişlerdir ${ }^{57}$. Bu bilgiler sekson köpeğinin ne denli güçlü olduğunu göstermektedir. Resmi törenlerde yapılan tertiplerde canbazlar, ciritçiler, cüceler, pehlivanlar, seksonlar ve ayılar türlü gösteri ve eğlencelerde bulunurlardı. Mısır valisi Mehmet Ali Paşa'nın oğlu namına yapılan ziyafette yukarıda isimleri sayılan kişi ve hayvanlar çeşitli oyunlar tertip etmişlerdir ${ }^{58}$. Gösterilerde seksonlar yalnızca ayıların üzerine değil fillerin üzerine de saldırtılıyordu. Seksonların saldırılarına dayanamayan fil bağırtılar içerisinde kaçmak zorunda kalmıştır ${ }^{59}$. Seksoncubaşının sorumlu olduğu ortayı idare etmek dışında farklı görevleri de vardı. Bunların başında devşirilecek çocukları toplamak geliyordu ${ }^{60}$. Kanuna göre devşirme yapmaları için ilk önce solakbaşılara sorulurdu. Eğer onlar ihtiyar olduklarını öne sürerek gitmek istemezlerse bu kez devşirmeyi yapmak üzere zağarcıbaşı, seksoncubaşı, turnacıbaşı gibi ağa bölükbaşılarına teklif götürülürdü ${ }^{61}$. Nitekim seksoncubaşının devşirme yaptığı belgelere yansımıştır. 1595 senesinin sonlarına doğru Anadolu ve Rumeli taraflarında seksoncubaşı, zağarcıbaşı ve bazı ocak ağaları acemi oğlanı toplamışlardır ${ }^{62}$.

\section{Yüzyılda Seksoncu ${ }^{63}$}

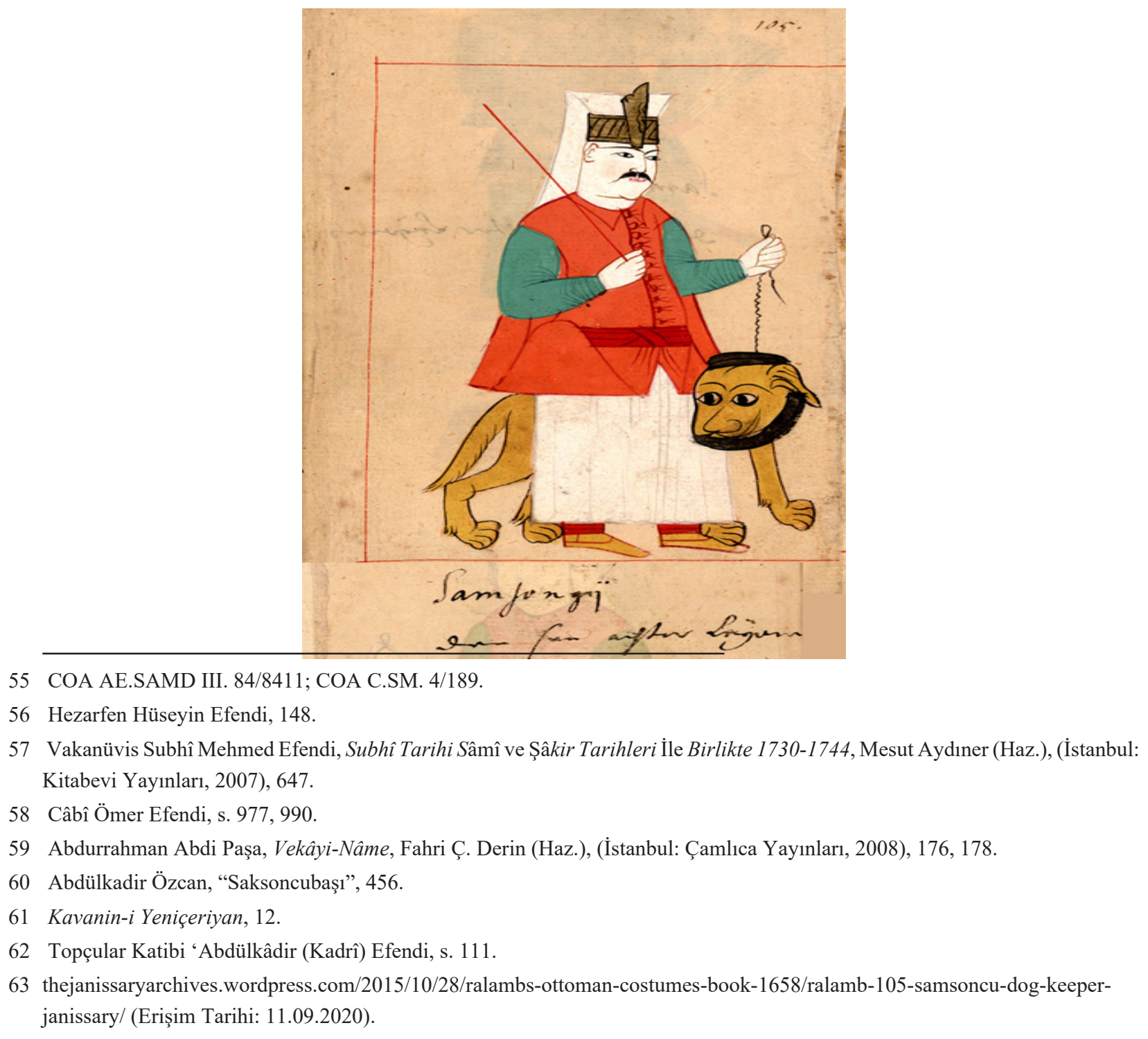


Kuruluş amacı padişahın av köpeklerine bakmak olan seksoncu ortası ilerleyen zamanlarda ocağın diğer ortaları gibi askerlik vazifesiyle sorumlu tutulmuşlardır ${ }^{64}$. Koçu, sekson cinsi köpeklerin seferde ordugâh muhafazasında kullanıldığını belirtmiştir ${ }^{65}$. Bunun yanı sıra Boğdan'da çıkan huzursuzluğun giderilmesi amacıyla 600 kişilik yeniçeri birliğinin başına seksoncubaş1, zağarcıbaşı ya da yayabaşının getirilerek Boğdan'daki Kapıcıbaşı Sinan Ağa'nın yanına gönderilmesi istenilmiştir ${ }^{66}$. Yine 1698 senesinde sefere katılmakla görevlendirilen seksoncubaşının maiyetinde 3.250 yeniçeri bulunmaktayd ${ }^{67}$. Her türlü verilen askeri görevi ifa etmekle sorumlu olan seksoncubaşı bunun yanı sıra Osmanlı Devleti'ne gelen elçilerin kendi ülkelerine să̆ salim ulaştırmada da vazifelendirilmiştir. Başkentten ayrılarak ülkesine gitmek isteyen İran elçisine 1740 yılında seksoncubaşı yanına aldığı bir yazıcı ve üç çavuş ile eşlik etmiştir. Seksoncubaşı ÜsküdarTokat-Kars güzergâhından giderek İran elçisini ülkesine yolcu etmiştir ${ }^{68}$.

16. yüzyıldan itibaren bostancılar da tazı, zağar ve sekson beslemeye başlamışlardı. 17 . yüzyılın başlarında iyi seksonlar artık bostancılar tarafından beslenilmiş ve iyi seksonlar bostancılar tarafından alındığ 1 için yetmiş birinci ortaya verilmez olmuştur. Yine de geleneği devam ettirmek adına padişah sefere gideceği zaman seksoncular bostancılardan emaneten iyi sekson alarak görevlerini ifa ederlerdi ${ }^{69}$. Ancak bu durum seksoncuların sekson besleme vazifelerinin tamamen pasifize olduğunu göstermemektedir. Her ne kadar bu alanda bostancılar öne çıkmış olsa da ilerleyen tarihte bostancı ocağıyla birlikte yetmiş birinci ortaya da sekson verildiği görülmektedir ${ }^{70}$. Bununla birlikte Evliya Çelebi'nin aktardığına göre 17. yüzyıl İstanbul'unda hem bostancılara hem de yeniçerilere ait toplamda iki adet samsonhane (seksonhane) bulunmaktadır ${ }^{71}$.

\section{Seksonların Temini}

Devletin sekson ihtiyacı imparatorluğun çeşitli yerlerinden ve hatta ülke sınırları dışından temin ediliyordu. İhtiyaç doğrultusunda padişahın emirlerine binaen görevlilere iletilen talimatlar ile temin edilen seksonların İstanbul'a gönderilmesi sağlanıyordu. 6 Temmuz 1573 tarihli hükme göre Taraklı Yenicesi, Göynük, İnegöl, Mudurnu, Akhisar ve Geyve kadılarından bölgelerinde padişah avlarında avlanabilecek işe yarar seksonların toplanarak bahçe ustalarından Mustafa ile İstanbul'a gönderilmesi istenilmiştir. Adı geçen kazalarda var olan seksonların sayısının bildirilmesi istenildiği gibi ayrıca sekson temini esnasında halkın rencide edilmemesi de tembih edilmiştir $^{72}$. 16. yüzyıldan itibaren bostancılarında sekson besledikleri yukarıda ifade edilmişti. Bundan dolayıdır ki temin edilecek seksonlar gerek bostancı ocağına gerekse yetmiş birinci ortaya

64 Pakalın, 112.

65 Reşad Ekrem Koçu, Yeniçeriler (İstanbul: Doğan Kitap, 2019), 83.

66 COA A.DVNS.MHM.d. 24/496.

67 COA AE.SMST.II. 90/9696.

68 COA C.HR. 46/2261; COA C.HR. 184/9183.

69 Kavanin-i Yeniçeriyan, 143; Uzunçarşıl1, Osmanlı Devleti Teşkilâtından Kapukulu Ocakları I, 202.

70 COA HAT 1140/45357.

71 Evliya Çelebi b. Derviş Mehemmed Z1llî, Evliya Çelebi Seyahatnamesi 1. Kitap, 253.

72 "Taraklu Yenicesi ve Göynük ve İnegöl ve Mudurnu ve Akhisar ve Geyve kadılarına hüküm ki şikâr-1 hümâyûn içun hâssa-i hümâyûnuma yarar sakson lazım olduğu bostancılarımbaşı Hasan dâme mecduhû ilâm itmeğin taht-ı kazanuzda bulunan yerlerden cem idüb getürmek içun bağçe ustalarından Mustafa irsal olundu buyurdum ki vardukda bu babda mukayed olub her kangınızın taht-ı kazasında hâssa-i hümâyûnuma yarar sakson bulunursa şimdiye değin alunu gelan yerden teallül itdirmeyüb miri içün mezkur alıverüb südde-i saadetime gönderesin ve her birinizin taht-ı kazasında ne mikdar sakson bulunub olduğunu yazub bildiresün amma bu bahane ile kimesneden celb ve ahz olunmakdan hazer eyleyesin.” COA A.DVNS.MHM.d. 22/260. 
veriliyordu ${ }^{73} .14$ Aralık 1609 tarihli emir ile Kocaeli, Hüdavendigar ve Bolu sancaklarından zağar, tazı ve sekson toplanılması istenilmiştir ${ }^{74} .1613$ yılında İstanbul'daki seksonların çoğunun helak olmasıyla birlikte şikâr-1 hümayun'da kullanılmak üzere Rumeli kadılarına, Eflak ve Boğdan voyvodalarına emir gönderilerek bulundukları yerlerde olan seksonlardan İstanbul'a gönderilmesi istenilmiştir ${ }^{75}$. Ortanın kuruluşunda seksonların kaynağının Eflak ve çevresinin olması ilerleyen yıllarda da sekson ihtiyacının bu bölgeden karşılanması için girişimleri beraberinde getirmiştir. Ocakta "güzide seksonların bulunması" kural olduğu için ihtiyaç duyulduğu vakit sekson temin etmek üzere Eflak ve Boğdan taraflarına başvurulmuştur ${ }^{76}$. Hatta bu bölgelerinde ilerisine gidilerek Avusturya ve Hotin'den sekson istenilmiştir. 24 Şubat 1757 tarihinde Hotin muhafızı Mehmed Paşa tarafından İstanbul'a 10 adet sekson gönderilmiştir. Seksonların nakli için Hotin muhafızı Mehmed Paşa tarafından tanesi 55 kuruştan olmak üzere 3 adet at arabası kiralanır. Toplamda İstanbul'a gönderilecek seksonların ulaşım ücreti için 165 kuruş ödenir. At arabalarının her biri 4 genç at tarafindan çekilen arabalardır. Seksonları İstanbul'a götürme vazifesi Yovanis veled-i Arsini, Solakoğlu Yovaniçe veled-i Marko ve Uzun Yovan veled-i Urso'ya verilir ${ }^{77}$. Avcıbaş1 aracılı̆̆ıyla Avusturya taraflarından 23 Mart 1804 tarihinde ise 12 sekson alınmıştır ${ }^{78}$. Ayrıca seksonlar devletlerarası diplomatik ilişkilerde bir hediye olarak takdim edilmiştir. Nitekim İngiltere ve Alman bölgelerinden birçok sekson hediye olarak Osmanlı padişahına gönderilmiştir ${ }^{79}$.

17. yüzy1lda Evliya Çelebi sekson cinsi köpeklerin ne denli değerli olduğunu ve onlara gösterilen rağbeti bu köpeğin yavrusunu alabilmek adına insanların kendi dişi köpekleriyle çiftleştirebilmek için 50 koyun verdiğini vurgulamıştır. Yine sekson köpeğinin değerini 500 koyun olarak belirtmiştir ${ }^{80}$. Çelebi'nin abartılı bir üslup kullandığ 1 herkesçe bilinmesine rağmen o dönemde sekson cinsi köpeklere gösterilen ilgiyi ortaya koyması açısından verdiği bilgiler değerlidir.

\section{Seksonların Bakımı}

Seksonların fizyolojik ihtiyaçlarını gidermek amacıyla ilk dönemlerde ekmek verildiği bilinmektedir ${ }^{81}$. İlerleyen yıllarda seksonlara hayvansal gıdaların verildiği görülmektedir. Bu doğrultuda İstanbul'daki seksonların yiyecek ihtiyacı işkembeci esnafı tarafından verilen işkembelerle karşılanıyordu ${ }^{82}$. 17. yüzyılda zağarcılar ve seksoncular ocağına her gün altışar

73 “... seksonciyan bostani ocă̆lyla dergah-ı ali yeniçerileri yetmiş bir meyanesine virilmek üzere ... lazım gelan seksonun tedarik ve irsali babinda ..." COA HAT 1140/45357.

74 COA A.DVNS.MHM.d.78/1464. Ayrıca Hayrabolu, Şumnu ve Pınarhisar kadılarına gönderilen emirde bostancıbaşı tarafından Samson ihtiyacı olduğu ifade edilmiş, gönderilen fermanla bu yörelerde devlete yarar samson var ise zapt edilmesi istenilmiştir. COA A.DVNS.MHM.d. 78/180.

75 COA A.DVNS. MHM.d. 81/563.

76 “...Seksonhane ocağında güzide seksonlar bulunması kaideden ocă̆-ı mezburda güzide seksonların adem-i vücuduna mebni kemâ fi's-sabık Eflak ve Boğdan taraflarından celbi lazımeden olduğu beyanıyla müntehab ve mümtaz olarak on res sekson tedarik birle dersaadet'e irsal ve ocağ-l mezkur tarafina teslim olunması tenbihatına havi...” COA HAT. 39/1952. Belgede geçen "seksonhane ocağı" ifadesinden kastedilen bostancı ocağı olmalıdır.

77 TS.MA.e. 1046/63.

78 COA HAT. 39/1952; Evliya Çelebi, "samson” adlı iri köpeklerin Alman taraflarından getirildiğini belirtir. Evliya Çelebi b. Derviş Mehemmed Zillî, Evliya Çelebi Seyahatnamesi 7. Kitap, Yücel Dağl1, vd. (Haz.), (İstanbul: YKY, 2003$), 334$.

79 Sunar, 39.

80 Evliya Çelebi b. Derviş Mehemmed Zıllî, Evliya Çelebi Seyahatnamesi 1. Kitap, 280.

81 Kavanin-i Yeniçeriyan, 143.

82 COA A.DVNS.MHM.d. 98/2. 
eşek yükü temizlenmiş işkembe veriliyordu ${ }^{83}$. Zağar ve seksonlara işkembe tedariki sağlayan işkembeci esnafina bu hizmetlerinden ötürü dışarıdan farklı kimselerin müdahale etmelerine izin verilmemiştir ${ }^{84}$. Çünkü işkembeci esnafi seksonlara verdiği işkembe karşılığında muhtesip, kul oğlanları ve yasakçılara vermeleri adet olan haftalıklardan muaf tutuluyordu ${ }^{85}$. Padişah av için İstanbul dışına çıktığında seksonların ihtiyaçları gittiği bölgedeki işkembeci esnafından karşılanmaya çalışılmıştır. Padişahın Edirne' de olduğu dönemde zağar ve seksonların karınlarının Edirne işkembeci esnafi tarafından doyurulması emredilmiştir ${ }^{86}$. Bostancılar tarafindan Kule bahçesi yakınlarında beslenen seksonlara koyun kelleleri verilmekteydi. Esasında buradaki seksonların sayısı 1780 yılına gelindiğinde artış göstermiş ve 28 olmuştur. Buradaki seksonlar için günlük kasapbaşından alınan 56 koyun kellesi yetersiz gelmiştir. Bundan dolayı bostanc1 ocağındaki seksonlar için günlük 86 koyun kellesi verilmiştir ${ }^{87}$.

Fizyolojik ihtiyacın yanı sıra seksonları kontrol etmek için bağlandıkları zincire ve tasmalara da ihtiyaç var idi. Yetmiş birinci ortadaki seksonlar için devlet her y1l "halta ve gerdane parası", "halka parası" adıyla tasma ücreti olarak 70 kuruş ödemektedir ${ }^{88}$. Ocakta yer alan seksonların ve miri ayıların zincirlerinin yapımı ve tamiriyle ilgilenmeleri üzere bazı kişilerin görevlendirildikleri tespit edilmiştir. Seksonlara ve ayılara lazım olan zincirleri yapmakla ya da tamir etmekle görevli olan 8 kıpti bulunuyordu. Demirci olarak kaydedilen bu 8 kıpti yaptıkları hizmet karşılığında cizye, ispenç, avarız, tekâlif-i örfiye ve şâkka gibi vergilerden muaf idiler. Zaman içerisinde 8 kıptinin ölmesi ve yerlerine görevlerini ifa edecek yakınlarının bulunmaması üzerine 1709 yılında İbrahim veled-i Baki adlı şahıs sekson ve ayıların zincirlerini yapma görevine atanmıştır. İbrahim de tıpkı kıptiler gibi yaptığı iş doğrultusunda vergilerden muaf tutulmuştur ${ }^{89}$. Kıptilerin görevleri sadece zincir yapmak değil aynı zamanda sekson ve ayılar için süpürge yapmakla da vazifelendirilmişlerdi ${ }^{90}$. Görüldüğü üzere seksonların yiyecek, tasma ve zincir masraflarını devlet ya doğrudan kendisi karşılamış ${ }^{91}$ ya da başkalarını yükümlü tutarak karşılatmıştır. 1826'ya kadar faaliyetlerine devam eden seksoncu ortası Yeniçeri ocağının kapatılmasıyla ortadan kalkmıştır.

83 Evliya Çelebi b. Derviş Mehemmed Zillî, Evliya Çelebi Seyahatnamesi 1. Kitap, 282.

84 COA A.DVNS.MHM.d. 98/2.

85 Uzunçarşıl1, Osmanlı Devleti Teşkilâtından Kapukulu Ocakları I, 201.

86 COA A.DVNS.MHM.d. 111/2427.

87 COA C.SM. 46/2318.

88 Farklı senelere ait ödemeler için bkz. COA C.SM. 132/6637; COA C.AS. 489/20429; COA C.AS. 1159/51564; COA AE.SİBR 2/172; COA AE.SİBR 2/173; COA C.AS. 427/17737; COA AE.SABH I 200/13361; COA C.AS. 91/4195; COA C.AS. $16 / 671$.

89 COA AE.SAMD III. 84/8411.

90 COA C.SM. 4/189.

91 Kavanin-i Yeniçeriyan, 208. 


\section{Yüzyılda Seksonculardan Bir Kesit ${ }^{92}$ (En Arkada Ellerinde Köpek Olanlar)}

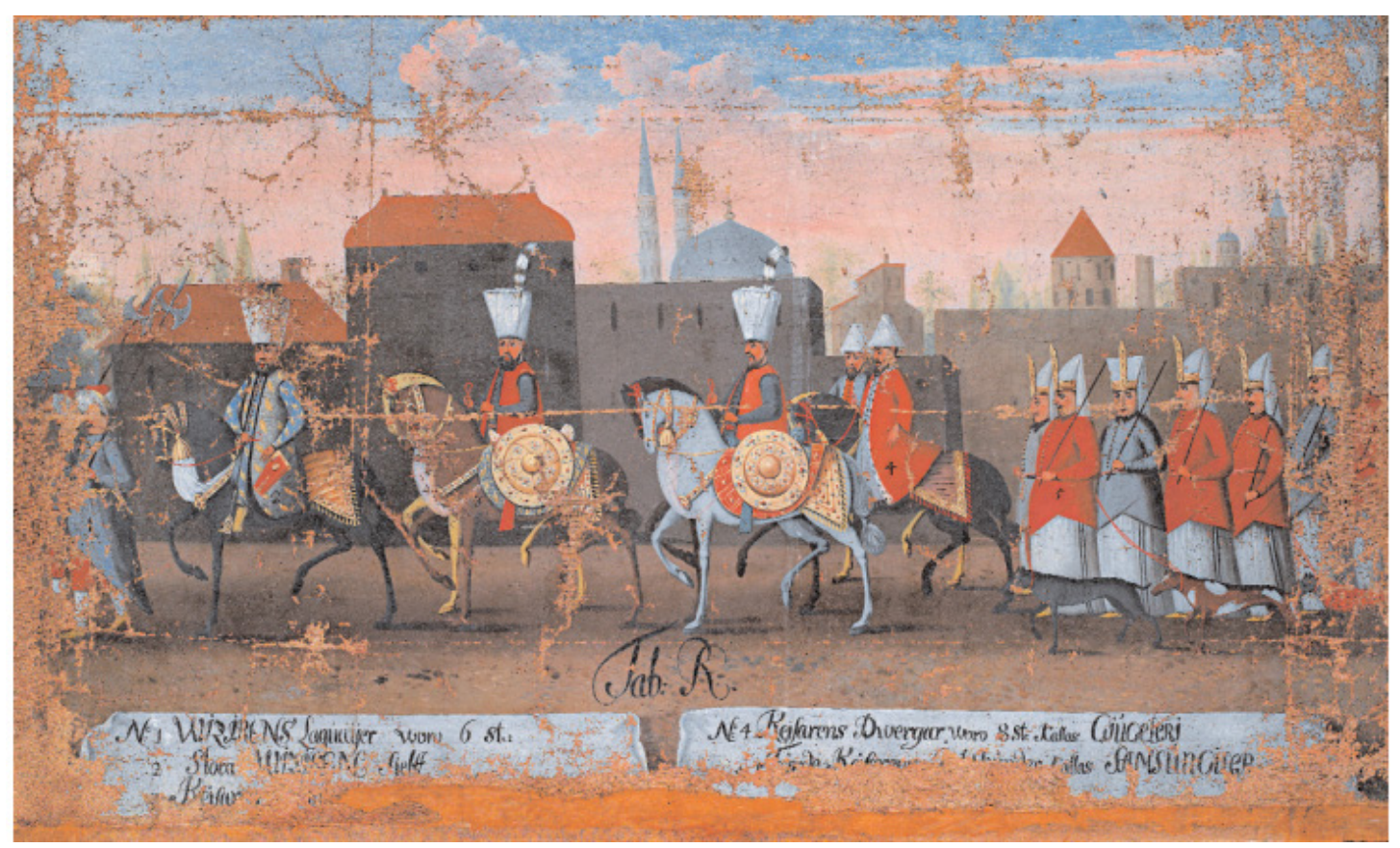

\section{Sonuç}

Fatih Sultan Mehmed döneminde kurulduğu rivayet edilen seksoncu ortası, zaman içerisinde sadece av maksatlı sekson beslememiş, baktıkları seksonları gösterilerde ve savaşlarda ordugâh muhafazasında da kullanmışlardır. Çalışma da tespit edilen hususların başında ocağa adını veren seksonların dışında ocakta aynı zamanda ayıların da beslenmekte olduğudur. Nitekim gösterilerde seksonun rakibi olarak ortaya çıkacak olan ayının da temin edilmesi gerekiyordu. Bu maksatlarla işlevini sürdüren seksoncu ortası sekson besleme görevini bir nevi bostancılara kaptırmalarıyla yavaş yavaş etkinliğini yitirir olsa da varlığını ve teşrifattaki yerini korumayı başarmıştır. Ocak ağaları içerisinde yer alan seksoncubaşı ortasını idare etmek ve seksonların bakımıyla yükümlü olmakla birlikte savaş esnasında bunların haricinde taraflarına tevdi edilen tüm vazifeleri yerine getirmiştir. Barış zamanında ise başta devşirilecek çocukları toplamak üzere verilen diğer görevleri ifa etmiştir. Av, gösteri, törenler ve savaşlarda kullanılan seksonların temini belirli aralıklarla gerek ülke içinden gerekse ülke sınırları dışından temin edilmiştir. Doğrudan teminin yanı sıra seksonların diplomasi alanında hediye olarak da İstanbul'a gönderilmesi sekson cinsi köpeğin önemini ayrıca ortaya koymaktadır. Hediye olarak gönderilen seksonların haricinde getirilen seksonlardan yeni nesil sekson üretmekte başarısız olunduğu ve eldeki seksonların tam anlamıyla muhafaza edilemediği görülmektedir. Bu şekilde faaliyetlerine devam eden seksoncu ortası varlığını 1826' da ocağın kaldırılışına kadar korumayı başarmıştır.

92 17. Yüzyılda İsveç Büyükelçisi Claes Rålamb’ın Yaptırdığı Tablolarla Avcı Mehmed'in Alay-ı Hümayunu, Pera Müzesi Yayınlar1, İstanbul 2006, s. 83. 


\section{Kaynakça}

\section{Arşiv Vesikaları}

Cumhurbaşkanlığı Devlet Arşivleri Başkanlığı Osmanlı Arşivi (COA)

Mühimme Defterleri (A.DVNS.MHM.d.): 22, 24, 78, 81, 98, 111, 131.

Bab-1 Defteri Teşrifat Defterleri (D.TŞF.d.): 26099.

Ali Emiri Sultan İbrahim (AE.SİBR): 2/172, 2/173.

Ali Emiri Mehmed IV (AE.SMMD.IV)

Ali Emiri Mustafa II (AE.SMST.II): 90/9696.

Ali Emiri Ahmed III (AE.SAMD III.): 84/8411.

Ali Emiri Osman III (AE.SOSM.III): 17/1112.

Ali Emiri Abdülhamid I (AE.SABH I): 200/13361.

Cevdet Askeri (C.AS): 16/671, 91/4195, 130/5795, 403/16640, 427/17737, 466/19465, 489/20429, $1159 / 51564$.

Cevdet Hariciye (C.HR): 46/2261, 184/9183.

Cevdet Saray (C.SM.): 4/189, 46/2318, 132/6637.

Hatt-1 Hümayun (HAT): 1436/59032, 39/1952, 1140/45357.

İbnülemin Askeriye (İE.AS.): 57/5147.

Topkapı Sarayı Müzesi Arşivi Evrakı (TS.MA.e.): 670/35, 690/33, 1046/63.

\section{Ana Kaynaklar}

Abdurrahman Abdi Paşa. Vekâyi-Nâme. Fahri Ç. Derin (Haz.). İstanbul: Çamlıca Yayınları, 2008. Ahmed Cevad Paşa.Tarih-i Askerî-i Osmanî, Kitab-ı Evvel: Yeniçeriler: Yeniçerilerin İhdasından İlgasına Değin Ahval-i Tarihlerini Bahisdir. İstanbul: Kırk Anbar Matbaası, 1299.

Câbî Ömer Efendi. Câbî Tarihi I. Mehmet Ali Beyhan (Haz.). Ankara: TTK, 2003.

Evliya Çelebi b. Derviş Mehemmed Zillî. Evliya Çelebi Seyahatnamesi 1. Kitap. Haz. Robert Dankof, vd. İstanbul: YKY, 2006.

Evliya Çelebi b. Derviş Mehemmed Zillî. Evliya Çelebi Seyahatnamesi 7. Kitap. Yücel Dağlı, vd. (Haz.). İstanbul: YKY, 2003.

Eyyubî Efendi Kanûnnâmesi. Haz. Abdülkadir Özcan. İstanbul: Eren Yayıncılık, 1994.

Hezarfen Hüseyin Efendi. Telhisü’l-Beyan Fi Kavanin-i Al-i Osman. Sevim İlgürel (Haz.). Ankara: TTK, 1998.

İstanbul Büyükşehir Belediyesi Atatürk Kitaplığı (İBBAK) K0456 Numaralı Yazma Eser.

İstanbul'un Uzun Dört Yılı (1785-1789) Taylesanizâde Hâfız Abdullah Efendi Tarihi. Feridun M. Emecen (Haz.). İstanbul: Tatav Yayınları, 2013.

Kavanin-i Yeniçeriyan, Tayfun Toroser (Haz.). İstanbul: Türkiye İş Bankası Yayınları, 2011.

Sayın, Abdurrahman Vefik. Tekâlif Kavaidi. Ankara: T.C. Maliye Bakanlığı Yayınları, 1999.

Topçular Katibi 'Abdülkâdir (Kadrî) Efendi. Topçular Katibi 'Abdülkâdir (Kadrî) Efendi Tarihi I. Ziya Yilmazer (Haz.). Ankara: TTK, 2003.

Vakanüvis Subhî Mehmed Efendi. Subhî Tarihi Sâmî ve Şâkir Tarihleri Ile Birlikte 1730-1744. Mesut Aydıner (Haz). İstanbul: Kitabevi Yayınları, 2007.

Yeniçeriler ve Bir Yeniçerinin Hatırası. Kemal Beydilli (Haz.). İstanbul: Pınar Yayınları, 2019.

17. Yüzyılda İsveç Büyükelçisi Claes Rålamb’n Yaptırdı̆̆ı Tablolarla Avcı Mehmed'in Alay-l Hümayunu, Pera Müzesi Yayınları, İstanbul 2006 


\section{Araştırma ve İnceleme Eserler}

Alkan, Mustafa, Gökbuğa, Ferdi. 'XVI. Yüzyılda Osmanlı Devleti'nde Av Teşkilatı'nın Silistre Sancağındaki Yapılanması”. Gazi Akademik Bakış Dergisi 17, (2015): 23-39.

Beydilli, Kemal. "Yeniçeri", TDVIA, C. 43, İstanbul 2013.

İlgürel, Mücteba. "Yeniçeriler", İA, MEB, C. XIII, İstanbul 1986.

İnalcık, Halil. Devlet-i Aliyye II. İstanbul: Türkiye İş Bankası Yayınları, 2014.

Kazım Kartal, “1840-1850 Tarihlerini Kapsayan Balıkesir Ve Bigadiç Kazaları Cizye Defterlerinin Tanıtımı Ve Tahlili”, Birey ve Toplum Sosyal Bilimler Dergisi 10, (2020): 27-42.

Koçu, Reşad Ekrem. Yeniçeriler. İstanbul: Doğan Kitap, 2019.

Marsilli, Graf. Osmanlı Imparatorluğunun Zuhur Ve Terakkisinden Inhitatı Zamanına Kadar Askerî Vaziyeti. M. Kaymakam Nazmi (Çev.). Ankara: Büyük Erkanıharbiye Matbaası, 1934.

Özcan, Abdülkadir. "Turnacıbaşı", TDVİA, C. 41, İstanbul 2012.

. "Zağarcıbaşı", TDVIA, C. 44, İstanbul 2013.

. "Rikab", TDVIA, C. 35, İstanbul 2008.

. "Saksoncubaşı", TDVIA, C. Ek-2, İstanbul 2016.

. "Biniş", TDVIA, C. 6, İstanbul 1992.

Pakalın, M. Z. Osmanl Tarih Deyimleri ve Terimleri Sözlüğü 3. İstanbul: MEB, 1983.

Sunar,M. Mert. “Osmanlı Devleti'nde Arslanhane”, Toplumsal Tarih, (2018): 36-41.

Uzunaslan, Abdurrahman. "Antik Roma'da Gladyatör Oyunları”. Süleyman Demir Üniversitesi Fen-Edebiyat Fakültesi Sosyal Bilimler Dergisi 12, (2005): 15-58.

Uzunçarşı1ı, İ.H. Osmanlı Devleti'nin Saray Teşkilatı. Ankara: TTK, 1988. . Osmanlı Devleti Teşkilâtından Kapukulu Ocakları I. Ankara: TTK, 1988.

Ünal, Mehmet Ali. Osmanlı Tarih Sözlüğ̈̈. İstanbul: Paradigma Yayınları, 2011.

Üçel Aybet, Gülgûn. Avrupa Seyyahların Gözüyle Osmanlı Ordusu (1530-1699). İstanbul: İletişim Yayınlar1, 2010.

Yıldız, Murat. Bahçıvanlıktan Saray Muhafızlı̆̆ına Bostancı Ocă̆ı. İzmir: Yitik Hazine Yayınları, 2012.

\section{4. İnternet Kaynakları}

thejanissaryarchives.wordpress.com/2015/10/28/ralambs-ottoman-costumes-book-1658/ralamb105-samsoncu-dog-keeper-janissary/ (Erişim Tarihi: 11.09.2020). 